\title{
Knowing What Things Look Like
}

Abstract: Walking through the supermarket, I see the avocados. I know they are avocados. Similarly, if you see a pumpkin on my office desk, you can know it's a pumpkin from its looks. The phenomenology in such cases is that of "just seeing" that such and such. This phenomenology might suggest that the knowledge gained is immediate. This paper argues, to the contrary, that in these target cases, the knowledge is mediate, depending as it does on one's knowledge of what the relevant kind of thing looks like. To make the case requires examining the nature of knowing what Fs look like. Is such knowledge to be understood as knowledge of a fact, or rather as a kind of ability? From the conclusion that the knowledge in the target cases is not immediate, the paper concludes that perception does not afford us immediate knowledge concerning objects' kinds.

\section{KEYWORDS:}

PERCEPTION, KNOWLEDGE, APPEARANCES, DOGMATISM, RECOGNITIONAL ABILITIES

\section{Knowing What Things Look Like*}

Walking through the supermarket, I see the avocados. I haven't seen any labels. I don't need to. I know those are avocados. Context might provide some hints. However, it hardly primes me to expect avocados in the very place I'm looking. In other cases, there are fewer hints. In April, I place a pumpkin on my office desk. The next time a colleague stops in to talk with me she see it. She knows it is a pumpkin, even if she's puzzled about why it's there.

In these cases, it doesn't seem to the perceiver like he or she is performing any reasoning. It seems as if one sees the thing and straightaway knows what it is. J.L. Austin describes the 
phenomenology well in a memorable example. If I see pig-like marks or find buckets of pigfood, I have evidence an animal is a pig. But if the animal

emerges and stands there plainly in view, there is no longer any question of collecting evidence; its coming into view doesn't provide me with more evidence that it's a pig, I can now just see that it is, the question is settled. (115)

In cases in which the phenomenology is of this "just see" sort, it's unsurprising that many epistemologists ${ }^{1}$ would conclude that the knowledge obtained is immed iate, it does not depend on one's knowing other propositions. ${ }^{2}$

This paper argues that in these target cases - knowing those are avocados in the supermarket, knowing it's a pumpkin in the office, knowing it's a pig in Austin's case - the knowledge is not immediate. It depends on other knowledge the person possesses, in particular on knowledge of facts about the avocados' looks.

Although there is little discussion of it in epistemology ${ }^{3}$, the suggestion that much perceptual knowledge depends on knowledge of looks is not particularly radical. It certainly fits well with what we ordinarily say:

'You'll need to take our Laz-Fly bus to get from the airport to campus. Do you know what our buses look like?"

- When I called Laz-Fly, an airport bus service, this is what I was asked.

"The department is by the library. Do you know what the library looks like?'

- A question from a professor wanting to direct me to the department where I would give a talk.

"I'll try to find it. What does it looks like?"

- A question a roommate might ask you when looking for your overdue library book. 
"What does poison ivy look like? How to recognize it."

- The title of a useful video on YouTube.

In these examples, it seems that the speaker is supposing that in order to know by sight whether the thing seen is an F, her hearer (or the speaker herself) needs to know what Fs looks like.

In this paper, however, I focus on our target cases. These cases are putative paradigms of immediate perceptual knowledge of object kinds. If we don't have immediate perceptual knowledge of object kinds in these cases, plausibly we never do.

\section{Basic terminology}

\subsection{Immediate knowledge}

Above, I glossed immediate knowledge as knowledge that doesn't depend on other knowledge. What sort of dependence matters?

I follow Alston's (1985) account. In some cases, you know a fact by virtue of knowing other facts suitably related to it, as when you know that your next meal will be after seven o'clock by virtue of knowing that the restaurant where you'll dine serves dinner only after seven. In other cases, such as knowing a simple mathematical truth, you might know a fact by virtue of relying on something that doesn't include knowledge of facts (for instance, reliable mathematical intuition). These examples suggest defining mediate knowledge as knowledge one has because one knows other facts and defining immediate knowledge as knowledge one has not, or not only, because one knows other facts.

However, these definitions won't quite do as they stand. Even if a belief is an instance of exclusively mediate knowledge, as in the meal example above, there will often be explanations of the subject's knowledge that do not appeal to the subject's knowledge of other propositions. 
Consider this one: you know your next meal will be after seven because the restaurant where you're going to dine only serves dinner after seven. This explanation cites simply a fact about when the restaurant serves dinner rather than your knowledge of that fact. Nevertheless, the knowledge about when you'll next dine is not immediate. What is needed, as Alston notes, is not just any explanation of a subject's knowledge, but an explanation of why a subject's belief is an instance of knowledge. Alston calls such explanations epistemizations. Facts about the restaurant's serving time don't by themselves explain why your belief that you'll dine after seven is a case of knowledge.

Alston defines mediate and immediate knowledge as follows:

"S's belief that $\mathrm{p}$ is mediate knowledge iff it is mediately epistemized, i.e., iff S's belief that $\mathrm{p}$ is epistemized by some relation this belief has to other epistemized beliefs of $\mathrm{S}$.

S's belief that $\mathrm{p}$ is immediate knowledge iff it is immediately epistemized, i.e., iff $\mathrm{S}$ 's belief that $\mathrm{p}$ is epistemized by something other than some relation this belief has to some other epistemized belief(s) of S." (74-5)

A welcome feature of these definitions is that they leave room for the possibility of knowledge that is both immediate and mediate. For just as you might know an unobvious theorem through two proofs, and thus by virtue of having two sources of mediate knowledge, so you might know an obvious theorem through both a proof as well through reliable mathematical intuition (arguably a source of immediate knowledge).

I propose to expand this account in several ways. To begin with, it is convenient to work with a definition in terms of the "somethings" such that a belief's being related to them in the appropriate ways explains why the belief is a case of knowledge. Call these "somethings" 
epistemizers. An epistemizer positions one to know a certain proposition. For instance, suppose I know that John is from Louisiana and I know that Louisiana is in the South Central US. My knowing these two facts positions me to know John is from the South Central US. Factors other than factual knowledge might position one to know. A reliably produced mathematical intuition that $\mathrm{p}$ (absent defeaters) arguably positions me to know that $\mathrm{p}$. The same goes for abilities.

Suppose I have the ability to know pumpkins by their characteristic look, and suppose I perceive this look in a pumpkin before me. Absent defeaters and in the right sort of environment at least, being so situated positions me to know the thing is a pumpkin. ${ }^{4}$

When you have an epistemizer for a proposition you are positioned to know it, but you may not know it. Knowing it requires taking advantage of your position to know. I assume that this "taking advantage" is in each case some manner of psychological basing relation. ${ }^{5}$ Depending on the character of the epistemizer, the basing relation takes different shapes. If the subject's epistemizer for $\mathrm{p}$ is the subject's knowing that $\mathrm{q}$ and that $\mathrm{r}$ the appropriate basing involves these propositions jointly comprising a reason for which the subject believes that $\mathrm{p}$. If no factual knowledge appears in the epistemizer the "taking advantage" should be understood differently. For instance, if the epistemizer includes a subject's having a recognitional ability, the sort of basing might be a matter of manifesting that ability in believing that $\mathrm{p}$. If it involves a particular sort of experience, the basing might be a matter of taking the experience at face value.

At this point, it might seem we have all we need for an adequate definition of immediate knowledge. Let's say a factor F appears in an epistemizer E iff either E is For E is a conjunctive factor and $\mathrm{F}$ one of its conjuncts. If $\mathrm{F}$ appears in an epistemizer, the epistemizer can be said to include $\mathrm{F}$. Then the definitions would be:

One has immediate knowledge that $\mathrm{p}$ iff one's belief that $\mathrm{p}$ is suitably based on an 
immediate epistemizer one has for $\mathrm{p}$.

One has mediate knowledge that $p$ iff one's belief that $p$ is suitably based on a mediate epistemizer one has for $\mathrm{p}$.

An epistemizer that one has for $\mathrm{p}$ is mediate if some factual knowledge one has appears in it, and otherwise it is immediate.

These definitions will suffice for most of our purposes. However, the definition of an immediate epistemizer neglects subtleties that will be crucial later in the paper.

Let me illustrate the general problem with an example. Consider understanding chess. To understand chess is to bear the understanding relation to chess. Plausibly, this is not identical to the state of knowing certain propositions, nor need it be identical to a conjunctive factor in which any state of factual knowledge appears as a conjunct. Still, plausibly, a person understands chess at least partly in virtue of having certain factual knowledge, for instance knowledge about how the pieces can permissibly move. Assume all this is true of understanding chess. Then consider a case in which some factual knowledge that helps ground one's understanding of chess also positions one to know something. For instance, suppose my knowledge that a rook can only move horizontally or vertically on the board helps ground my understanding of chess and also positions me to know that a rook cannot move on the diagonal. Then my understanding of chess arguably is a derivative epistemizer of the latter fact: it positions me to know that fact only in virtue of my having another epistemizer that positions me to know it. Suppose I believe rooks can't move on the diagonal in a way suitably based on my understanding. Do I have immediate knowledge? It doesn't seem so. Intuitively, the mediate epistemizer is doing the real work, and yet, by the above definitions, my belief counts as immediate knowledge.

A small change in the definition of an immediate epistemizer avoids this problem: 
An epistemizer, $\mathrm{E}$, one has for $\mathrm{p}$ is immediate iff: (i) no factual knowledge one has appears in $\mathrm{E}$, and (ii) one has no mediate epistemizer, $\mathrm{E}^{*}$, for $\mathrm{p}$, which is such that $\mathrm{E}$ positions one to know that $\mathrm{p}$ only in virtue of $\mathrm{E}^{*}$ positioning one to know that $\mathrm{p} .{ }^{6} 7$

\subsection{Liberal dogmatism}

Next, we turn to epistemological positions relevant to our inquiry. Let us start with:

Dogmatism: Perception affords us immediate knowledge of some non-trivial propositions about how things are in the world outside us. (cf. Pryor (2000))

Dogmatism makes an existential claim. It therefore doesn't by itself have implications for our target examples. Some dogmatists think the range of worldly immediate knowledge is highly restricted, including only low-level properties, such as a thing's color or shape. But many dogmatists follow the "just see" phenomenology more closely. I see a couch. I know it's green and I know it's a couch. In neither case do I perform any conscious reasoning from other knowledge. ${ }^{8}$ Why not treat the two cases alike, at least in the absence of strong evidence from psychology that $I$ - and not only my visual system - rely on other knowledge for the couchproposition but not for the green-proposition? This points in the direction of:

Liberal dogmatism: perception affords us immediate knowledge concerning objects' kinds and not only their sensible qualities.

If liberal dogmatism is true, it is hard to see what better candidates there could be for cases of immediate perceptual knowledge of object kinds than our target cases. I therefore assume that if I can show that the knowledge in the target cases is not immediate, I will have refuted liberal dogmatism. In the next section, I present the main argument of the paper, the argument that the knowledge in the target cases is not immediate. 


\section{The only-because argument}

We stated our official definition of immediate knowledge in terms of epistemizers. Of course, one won't find this term used in folk epistemological discussion. But there is a familiar folkfriendly way of explaining where knowledge comes from which gets precisely at issues of epistemization. I will give two examples.

Example 1: Scott's height. My friend is getting married. I've heard much from her about her friend Scott. I've emailed with Scott a few times to work out the plans for the wedding details (who will give the first toast, etc.). I've never seen him. Shortly before the dress rehearsal, my friend tells me "Scott is extremely tall: 7 feet!" At the rehearsal, I see one person towering over the others. I know it's Scott. Suppose my wife is with me but wasn't part of the earlier conversation. She has no idea that it is Scott.

In this case, how do I know it's Scott? Answer: I know it's Scott because I know that Scott is extremely tall. That's the only way I have of knowing it's Scott. For, if I didn't know Scott was extremely tall, I would have no way of knowing it's Scott. I'd be in my wife's position, and so have no idea. Thus, I know it's Scott only because I know Scott is extremely tall.

Example 2: The Bells Case. For various reasons, the school bus drivers at West Middle School cannot always count on using the North parking lot; sometimes they have to use the South lot. The school has developed a policy. They use the normal single ring if the buses will arrive at the North lot and two rings if they will arrive at the South lot. A veteran middle-schooler, Tom, and friend Markus, who's new to the school, both hear the two rings at the last class period. Tom hears knows the buses will be at the South lot. 
Markus wonders why they are ringing twice. He doesn't know that the buses will be at the South lot.

How does Tom know the buses will be at the South lot? Tom can know the buses will be at the South lot because he knows that two bells indicate the buses will be at the South lot. And that's the only way he has of knowing the buses will be at the South lot. If he didn't know this, he wouldn't have any way of knowing where the buses would arrive (without asking, etc.). He'd be in Markus's position and Markus has no idea where the buses will be. Thus, Tom knows that the buses will be at the South lot only because he knows that two rings indicate the South lot.

With these two examples in place, let's return to the supermarket case (the other target cases are similar). We can give a similar explanation of how I know those are avocados. I know what avocados look like, and this gives me a way to know those are avocados. Moreover, it's the only way I have of knowing they're avocados. If I didn't know what avocados look like, I would have no way of knowing they're avocados (without getting more information by asking or finding a label). Suppose I am with my friend Dmitri from avocado-deprived northerly climes, who knows no more about avocados than I did before I knew what they looked like. I might then say: "if I didn't know what avocados looked like, I'd be in the position of Dmitri here, who has no idea what these are." So, I know those are avocados only because I know what avocados look like.

The counterfactual reasoning we naturally employ in thinking about these cases is forward-tracking rather than back-tracking. We do not ask, on the supposition that the subject lacks the relevant background knowledge, what would have had to been the case to make the lack of background knowledge possible, before turning to the question whether the subject would still have the target knowledge. Such backtracking reasoning would lead to very different 
conclusions. Consider this reasoning about the Scott's height case: if I didn't know Scott was extremely tall, I wouldn't have asked the bride about Scott but might well have earlier googled Scott and seen a photograph of his face, in which case I would still have known it was Scott at the rehearsal but on a different basis than I in fact do. Again, this is not the sort of reasoning we employ in any of the three cases above. What we are doing, rather, is surgically removing one piece of knowledge and then "running" the epistemizing forward with that surgical change. We are intervening in the terminology of causal modeling theorists (Pearl (2009)). In what follows, I will assume this forward-tracking interpretation of the relevant counterfactuals. ${ }^{9}$

If we try to put these explanations of how we know into the form of an argument, we'd have this:

1. $\mathrm{S}$ knows that $\mathrm{p}$ and $\mathrm{S}$ knows that $\mathrm{q}$ (where knowing q gives $\mathrm{S}$ a way to know that $\mathrm{p}$ ).

2. If S didn't know that $\mathrm{q}, \mathrm{S}$ would have no way to know that $\mathrm{p}$.

So, 3. The only way $\mathrm{S}$ has to know that $\mathrm{p}$ is from his knowledge that $\mathrm{q}$.

So, 4. S knows that $\mathrm{p}$ only because $\mathrm{S}$ knows that $\mathrm{q}$.

This is not a deductively valid argument. (3) does not follow from (1) and (2). It is logically possible for one to have several distinct ways of knowing that $\mathrm{p}$, even though were one to lack a particular one of these ways, one wouldn't have the other ways of knowing $\mathrm{p}$ at all. This is true even if distinctness is being understood so that the two ways of knowing have no element in common. Yes, we should want to know why distinct ways of knowing should be connected in this way, but it isn't ruled out logically. At best (1) - (3) constitute a good prima facie reason in a particular case for believing (4).

I propose to recast this argument deductively, using the terminology from the previous section. I recast the talk of "ways to know" in terms of epistemizers. In basic outline, the 
argument goes like this. ${ }^{10}$ Suppose $\mathrm{S}$ knows that $\mathrm{q}$, and that this knowledge helps position $\mathrm{S}$ to know that $\mathrm{p}$. Then $\mathrm{S}$ has an epistemizer for $\mathrm{p}-$ call it $\mathrm{E} 1$ - which includes $\mathrm{S}$ 's knowledge that $\mathrm{q}$. The question is whether S has some other epistemizer, E2, for p, which doesn't include S's knowledge that q. We then test this hypothesis. If there is such an E2, we should expect that by surgically intervening and 'turning off' E1, we would leave E2 and its line of epistemic influence unaffected, so that E2 would continue to position S to know that p. However, if we surgically intervene in this way, S wouldn't be in any position to know that $\mathrm{p}$. Thus, there is no such E2. ${ }^{11}$

Here is the argument schema in full dress:

\section{The only-because argument schema:}

1. $\mathrm{S}$ knows that $\mathrm{p}$, and $\mathrm{S}$ knows that $\mathrm{q}$ (where knowing that $\mathrm{q}$ helps put $\mathrm{S}$ in a position to know that $\mathrm{p})$.

2. If $S$ has an epistemizer for $p$ that does not include $S$ 's knowledge that $q$, then if $S$ didn't know that $\mathrm{q}, \mathrm{S}$ would still be in a position to know that $\mathrm{p}$ - thanks to the other epistemizer.

3. However, if S didn't know that $\mathrm{q}, \mathrm{S}$ wouldn't be in a position to know that $\mathrm{p}$.

So, 4. Every epistemizer $\mathrm{S}$ has for $\mathrm{p}$ includes $\mathrm{S}$ 's knowledge that q. (from 1, 2 and 3)

Put colloquially: $S$ is in a position to know that $p$ only because $S$ knows that $q$.

So: 5. S's knowledge that $\mathrm{p}$ is not immediate. (from 1 and 4 )

Consider again Scott's height. If I have an epistemizer for the proposition that it's Scott which doesn't include my knowledge that Scott is so extremely tall, then we should expect me still to be in a position to know it's Scott even if we wiggle off the variable "I know that Scott is extremely tall." But this counterfactual is false: I'd be in no such position. It follows that my 
knowledge that Scott is extremely tall appears in every epistemizer I have for it's Scott. Thus, my knowledge is not immediate.

The same goes, I claim, for the bells case and indeed the supermarket case:

\section{The only-because argument - supermarket case:}

1. I know that those are avocados, and I know what avocados look like (where the latter helps put me in a position to know that those are avocados).

2. If I have an epistemizer for those are avocados that doesn't include my knowledge of what avocados look like, then if I didn't know what avocados look like, I'd still be in a position to know that those are avocados.

3. However, if I didn't know what avocados look like, I wouldn't be in a position to know that those are avocados.

So, 4. Every epistemizer I have for those are avocados includes my knowledge of what avocados look like. (from 2-3)

So, 5. My knowledge that those are avocados is not immediate. (from 1 and 4)

This argument seems as compelling as the only-because arguments for the Scott's height and Bells cases. I know what avocados look like, and this knowledge, together with other knowledge, positions me to know the things before me are avocados. Do I have an epistemizer that doesn't include this knowledge? If I do, then if I lacked the knowledge of what they looked like, I should still be positioned to know, thanks to this other epistemizer. But if I lacked that knowledge, I'd be in no position to know those are avocados.

If the argument (1)-(5) is sound, then given our assumption that if liberal dogmatism is true then the knowledge in this case is immediate, it follows that liberal dogmatism is false. 
However, there is a hitch. Together with (1), (4) seems to entail (5), yet this might be because one assumes that knowledge of what avocados look like is factual knowledge. If this "intellectualist" assumption is false, the entailment might fail. Suppose my knowledge of what avocados look like is similar to what many anti-intellectualists about knowhow say knowhow is: a kind of ability or range of abilities not grounded in knowledge of facts. If this were so, then despite the fact that my knowledge of what avocados look like figures in every epistemizer of my belief that those are avocados, it wouldn't follow that factual knowledge appears in every such epistemizer. Thus, my knowledge could still be immediate, even if the argument up through (4) is sound. The corresponding step in the Scott's height case and the Bells case, by contrast, does go through, since the relevant knowledge in those cases is factual.

I devote sections 3-5 of the paper to examining candidate theories of knowing what Fs look like, with an aim to determining whether there are plausible theories of knowing what Fs look like that would provide the resources to block the move from step (4) to (5) in the onlybecause argument. In section 6, I consider objections to the earlier steps of the argument, prior to step (4). In the final section, 7, I briefly consider whether we can remain dogmatists if my main argument is sound. I suggest some reasons for optimism. However, the resulting dogmatism is significantly attenuated, not liberal and I think not particularly moderate.

\section{Intellectualism and Anti-Intellectualism}

The idea that knowledge of what Fs look like isn't factual knowledge has prima facie plausibility. To see this, let's briefly compare the case of knowing how.

Consider a familiar sort of example: knowing how to ski. Some skiers may be able to offer extensive details about how they do it. Many will not, or will offer false accounts. Compare 
my knowledge of what avocados look like. It is true that I can describe their looks to some extent, but I couldn't do justice to their distinctive look without much effort (and preferably with the help of a sample or photograph). Even then, I might well get a number of details wrong. When we turn to my knowledge of what individual people look like my descriptive powers are even less impressive. Considerations like these provide reason to take seriously the possibility that a kind of anti-intellectualism is true of some knowledge of what Fs look like, and in particular the knowledge of what Fs look like in the target cases.

We need a working characterization of intellectualism vs. anti-intellectualism about knowing what Fs look like. I use the following formulations, borrowed from Bengson and Moffett (2011b, 162-3). The formulations use 'constitutes' as short for 'is identical to or is grounded at least in part by':

Intellectualism: knowing what Fs look like, in every case, is constituted by having correct cognitive propositional attitudes concerning Fs, that is, by having factual knowledge, true belief, or true propositional seemings.

Anti-intellectualism: knowledge what Fs look like, in at least some cases, is not constituted by having correct cognitive propositional attitudes concerning Fs. These "isms" do not specify necessary and sufficient conditions for knowing what Fs look like. They are general doctrines rather than particular candidate theories. My goal in the next section is determine whether there is a plausible theory, intellectualist or anti-intellectualist, which would allow one to block the last step of the only-because argument, and thus would allow one to concede that knowledge of what the relevant Fs look like in the target cases is included in every epistemizer the subject has for the proposition that the things seen are Fs while denying that this guarantees that all these epistemizers are mediate. 
I close this section with an important constraint on theories of knowing what Fs look like, in addition to the usual ones (extensional adequacy, non-circularity). In the target cases supermarket, office, Austin's pig case - the subject's knowledge of what the relevant Fs look like helps positions her to know from the things' looks that they are Fs, and to know this with the "just see" phenomenology. We should therefore require of a theory of knowing what Fs look like that it have the resources to explain how knowing what the relevant Fs look like could perform such a role in these cases. We will call this constraint the just-see constraint.

\section{Intellectualist theories}

Let us begin with standard intellectualism. This is the view that knowledge of what Fs look like is factual knowledge. But what factual knowledge about Fs is it? And is there a way for standard intellectualist theories to satisfy the just-see requirement?

Within the semantics of questions, knowledge-wh ascriptions are taken to embed whquestions. The dominant view is that such sentences are true just in case the subject knows a truth that is an adequate answer to the embedded wh-question. ${ }^{12}$ If we took these semantic theories to tell us about the nature of knowledge-wh, we would conclude that to know what Fs look like is to know a truth that is an adequate answer to the question what do Fs look like?

What would such answer be? On a natural proposal, the answer takes this form: Fs look

like $[N P]$, where ' $[\mathrm{NP}]$ ' is a noun phrase and 'like' has expresses similarity. ${ }^{13}$ However, this isn't a promising approach for intellectualists. It wrongly makes knowledge of comparative truths about Fs' looks sufficient for knowing what Fs look like. Suppose that Tom and Charlie are identical twins. Merely knowing that Tom looks like Charlie isn't sufficient for knowing what Tom looks like. You might not know what Charlie looks like, after all. Similarly, merely 
knowing that violas look like violins except that they're a bit bigger isn't sufficient for knowing what violas look like. You might not know what violins look like. ${ }^{14}$

A more promising approach is to identify knowledge of what Fs look like with knowledge of a suitable non-comparative truth about Fs' looks. In what follows, this is how we will understand standard intellectualis m.

Which fact is known, then, in knowing what Fs look like? Here are several candidates:

(a) Fs look W.

(b) The way Fs look is W.

(c) What Fs look like is W. (Brogaard 2011).

(d) Fs are W.

where ' $\mathrm{W}$ ' picks out the look of Fs. ${ }^{15}$

Many complications arise when we turn to the identity of $\mathrm{W}^{16}$, complications that affect the intellectualist and anti-intellectualist equally. Fortunately, these details don't matter for the main purposes of this paper (for a brief tour of some of the details see the Longer Note). The story will proceed in roughly the same way regardless of how we handle them. To keep things as simple as possible, at the expense of losing fine detail, I will work with (a):

Simple intellectualist theory: knowing what Fs look like is knowing the fact that Fs look $\mathrm{W}$, where $\mathrm{W}$ is the look of Fs.

Does this simple theory satisfy the just-see requirement? That is, under the simple theory, could my knowledge of what avocados look like help position me in the supermarket to know from the things' looks that those are avocados and to do so with the "just see" phenomenology? The simple intellectualist can say that, just as in the Scott's height case and the Bells case, the best account appeals to other facts known. In the Scott's height case, the best account appeals to 
knowledge that the man seen is considerably taller than everyone else here; in the Bells case, it appeals to knowledge that the bell has rung twice. In the supermarket case, it appeals to knowledge that those things (the avocados seen) look a certain way $\mathrm{W}$, together with background knowledge that things that look like avocados in normal cases like the one in question are avocados. These pieces of knowledge combine to yield the knowledge that the things are avocadoes via an argumentative structure such as (i) - (v):

(i) Avocados look W.

(ii) Those things look W.

So, (iii) those things look like avocados (that is, it looks the way avocados do). (from (i) and (ii))

(iv) Things that look like avocados in normal situations like this are avocados.

So, (v) those are avocados. (from (iii) and (iv))

Note that the step to (v) is not deductive. Rather if you know (iii) and (iv), you have a very good defeasible reason to think (e) is true, strong enough for knowledge.

The above story shows how knowledge of what avocados look like could help position me to know those are avocados in the supermarket case. But does it explain how such knowledge could have the "just see" phenomenology?

One might worry that mediate knowledge couldn't have the "just see" phenomenology. However, while phenomenological and epistemic immediacy may often go together, this is not always the case. To use an example from Senor (2014), I look at the sunset and know it's a sunset. My knowledge that it's a sunset is not immediate. It depends on my knowledge that it is evening. But I just see that it is a sunset; it doesn't feel like I'm inferring. Or again, on Halloween night, upon hearing someone knock on the door, I know that a trick-or-treater is at the 
door, without any phenomenology of reasoning. But my knowledge is mediated by the knowledge it is Halloween.

Even if there is no in-principle obstacle to mediate knowledge having the "just see" phenomenology, can the intellectualist do anything to explain why the resulting knowledge in the target cases should have this phenomenology rather than that of reasoning? I think so.

Some ideas from Audi provide help. Audi (2003, 154-5) distinguishes reasoned beliefs and beliefs for reasons. The former come about through a conscious episode of reasoning. The latter don't but are still explained by our having other beliefs. As he points out, when a belief is based on a reason that provides very strong undefeated support in an obvious way from familiar background knowledge, typically we don't have the phenomenology of reasoning. The sunset and Halloween examples are not at all unusual: they are instances of this general pattern, as are the examples of Scott's height and Bells. So are the supermarket case and the other target cases. $^{17}$

Finally, the simple intellectualist can improve her account of how the target knowledge could have the "just see" phenomenology by appealing to ways the look $\mathrm{W}$ is conceived. Suppose I know that avocados look $\mathrm{W}$, conceiving of $\mathrm{W}$ via a property list: avocados are dark, rough-textured, and oval. If my knowledge involves such a conception, putting it to use to conclude that those are avocados would presumably have the phenomenology of checking off features "yes, these are dark, rough-textured, oval, and so..." But if my thinking of the look is direct, we can see better how the resulting knowledge could have the required phenomenology.

Consider an example from Peacocke $(1986,49-50)$. An anaesthetized patient can think of a gesture practically and be surprised to see the movement of his limbs. In such a case, the patient thinks with surprise this gesture (thought of practically) is the same as that one (thought 
of demonstratively). These are distinct ways of thinking, both direct, insofar as they do not involve thinking of a thing via a property list. Similarly, the intellectualist can appeal to ways of thinking to explain how you can learn this is that look again when you see a certain look again. In such a case, you think of a look demonstratively and realize it is the same as a look thought of in some other way. What is this other way? In the case of knowhow, it may be a practical mode of presentation (cf. Stanley and Williamson (2001)). What is it in the case of the knowledge of looks in the target cases? How is $\mathrm{W}$ being conceived in knowing that those are avocados via the inferential structure (i) $-(\mathrm{v})$ ?

There are several possibilities. One might appeal to special concepts. Peacocke (1993) and Recanati (2013) invoke recognitional concepts, ways of thinking such that to think of something in that way requires the ability to recognize the referent. Alternatively, one might appeal to what Papineau (2006) refers to as perceptual concepts, concepts involving stored sensory templates established when we perceive an object or feature and which are reactivated upon subsequent perceptual matches as well as in imagination. ${ }^{18}$ Another possibility is to appeal to acquaintance relations rather than to concepts. Thus, Tye $(2009,133)$, in discussing knowing what it is like to experience red, tells us that the factual knowledge that this is what it is like to experience red is "based" on knowledge by acquaintance with the relevant phenomenal property (which he takes to be the color red). ${ }^{19}$ I will not attempt to adjudicate these accounts here. What matters is that each of them identifies a direct way of thinking of a look, which helps explain the "just see" phenomenology in the target cases. ${ }^{20}$

Plausibly, then, the simple intellectualist theory can meet the just-see constraint by asserting the following: first, in the target cases, the knowledge that Fs look W is familiar background knowledge that provides very strong undefeated support in an obvious way for the 
proposition that the perceived thing is $\mathrm{F}$ (through the structure (i) - (v)); and second, in the target cases, the relevant look is conceived in a suitably direct way.

The standard intellectualist theory, thus, looks promising. If this theory were correct, then the last step of the only-because argument would of course go through.

\subsection{Other varieties of intellectualism}

One can be an intellectualist without accepting standard intellectualism. One might accept an analogue of Bengson and Moffett's (2011b) “non-propositional intellectualism” about knowhow, according to which knowing what Fs look like is not factual but rather objectual knowledge - it is knowledge of a way, a way of looking. The view counts as intellectualism because it holds that this objectual knowledge is partially grounded in factual knowledge or at least correct cognitive propositional attitudes. Another way to be an intellectualist without accepting standard intellectualism is to identify knowing what Fs look like with the possession of some correct cognitive propositional attitude that fails to imply factual knowledge, and for instance with true belief or true seeming. (It would be implausible to replace it with something stronger like epistemic certainty.) Consider a position similar to Cath's $(2011,133)$ seemings analysis of knowhow: knowing what Fs look like is having a correct seeming state whose content is Fs look $W$, perhaps under the right mode of presentation. Other positions might appeal to true belief rather than seeming (cf. Zardini 2013).

Building on earlier observations from Ryle, Bengson and Moffett give linguistic evidence against standard intellectualism about knowhow. If you possess factual knowledge, you should be describable as "being right," "being justified" and "not being right by accident, and it should be appropriate to ask "and are you certain?" As they point out (2011b, 182-5), such descriptions 
seem at best peculiar and at worst category mistakes when applied to knowhow. One might hope to use similar considerations to argue against standard intellectualism about knowing what Fs look like. However, such hopes are dashed. When someone knows what avocados look like, we can appropriately describe the person as "right about what avocados look." Consider, also: "S knows what Fs look like, and therefore S's belief about what they look like is justified." Or: "S knows what Fs look like and so S isn't right simply by accident about what they look like." Finally, if someone says, "I know what avocados look like," it does not seem problematic to ask, “Are you certain about what they look like?" These all seem unproblematic, or at least no more problematic than similar descriptions and questions applied to cases of knowledge-wh that plausibly reduce to factual knowledge. Consider: "Sarah knows which day of the week is recycling collection day, and therefore Sarah is right about which day is recycling collection day, is justified and even certain in her belief about this."

In fact, the sorts of considerations just given undermine theories that identify knowing what Fs look like with a propositional attitude that falls short of factual knowledge. Suppose I am accidentally correct in believing that avocados look W, say because it just happened to pop into my mind that they look W. Intuitively, I don't know what avocados look like - I'm just right by luck. An intellectualist may capture this nicely by insisting that knowing what avocados look like requires knowing that they look $\mathrm{W}$. By contrast, no such considerations seem to show that intellectualists about knowhow should identify knowhow with factual knowledge rather than some propositional attitude that falls short of it. Suppose that, although you can replace a light fixture with ease, you believe you can do so in the relevant way (thought of under a practical mode of presentation) only because you happened to read a correct set of instructions in a largely inaccurate "how to" book. There is little temptation to think that you can't have the knowhow 
owing to the fact that your belief is accidentally correct (cf. Cath 2011: 115). Thus, while we cannot set aside versions of intellectualism about knowhow that identify it with a propositional attitude that falls short of factual knowledge, we can set aside the corresponding versions of intellectualism about knowing what Fs look like.

Consider, now, the Bengson and Moffett-inspired account of knowing what Fs look like. Wouldn't this view enable one to block the last step of the only-because argument? ${ }^{21}$ Just because knowledge of a way of looking is included in every epistemizer I have for the proposition that those are avocados, it doesn't follow that my knowledge of that proposition isn't immed iate.

So far, so good. However, like everyone else, this theorist needs to explain how her account satisfies the just-see constraint. My knowing what avocados look like in the supermarket case helps position me to know those are avocados. How does it do this? (The phenomenology is not crucial here, only the positioning to know.) Merely knowing a way of looking that is in fact the way avocados look isn't enough, nor is it sufficient if we also add that I know the things before me look W and I know that in general what looks like an avocado typically is an avocado. Dmitri from northerly climes might know all this (see note 21). Do matters improve if take knowing a way of looking to amount to having a "complete conception" of that way of looking ((Bengson and Moffett 2011b, 188))? It doesn't seem so. Why can't Dmitri know the way of looking to the last detail, and be able to recognize it again on sight, but still not associate it with the category avocado?

The way out is to appeal to the correct cognitive attitudes that, according to the account in question, ground the objectual knowledge. But this won't do unless those attitudes are knowledge. ${ }^{22}$ Mere true belief will not help position me to know that those are avocados, nor will 
mere seeming, unless other conditions are added to yield knowledge. Indeed, in their earlier paper, Bengson and Moffett $(2007,50)$ themselves take knowing how to $\varphi$ to be grounded in part in factual knowledge, concerning a way to $\varphi$, that it is a way to $\varphi$. A parallel account would take knowing what Fs look like to be partly grounded in knowing of a way of looking, had by Fs, that it is had by Fs. The just-see constraint would then be satisfied in the same way as it is on the simple intellectualist theory above: my knowing what avocados look like, in the supermarket case, would be grounded in my knowing that Fs look W, which would position me to know that those are avocados via the inferential structure (i) - (v).

Where does this leave the non-propositional intellectualist with respect to the onlybecause argument? Once we consider the possibility that my knowing what avocados look like helps position me to know those are avocados only by virtue of my factual knowledge positioning me to know it, we see we need to make adjustments to the argument. Talk of "every epistemizer" becomes a more delicate matter, given that some depend on others. However, the argument can go forward much as before with a small change in step 2 (the new material is highlighted) and corresponding changes in later steps:

2'. If I have an epistemizer for those are avocados that includes neither my knowledge of what avocados look like nor factual knowledge I have that grounds that knowledge, then if I didn't know what avocados look like, I would still be in a position to know that those are avocados.

The step from 4 to 5 then becomes:

So, 4'. Every epistemizer I have for those are avocados includes either my knowledge of what avocados look like or some factual knowledge that grounds that knowledge.

So, 5. My knowledge that those are avocados is not immediate. 
Our non-propositional intellectualist has no way to reject this last step. Take any epistemizer, E, I have for those are avocados. Either E includes factual knowledge or it includes knowledge of what avocados look like. If the former, $\mathrm{E}$ is not an immed iate epistemizer. If the latter, then insofar E positions me to know those are avocados only thanks to my having a mediate epistemizer, $\mathrm{E}^{*}, \mathrm{E}$ is not an immediate epistemizer. Thus, I lack an immediate epistemizer and hence the resulting knowledge isn't immediate.

This conclusion about the Bengson-Moffett-inspired form of non-propositional intellectualism applies to other non-standard forms of intellectualism. Whatever knowing what Fs look like is, if it is not factual knowledge, one would have to explain how it helps position the subject to know the relevant facts in the target cases. The most plausible accounts claim that the knowledge of what Fs look like helps position the subject to know courtesy of its being grounded in factual knowledge that helps position the subject to know. Thus, non-propositional intellectualists should not object to the last step in the appropriate only-because argument.

\section{Anti-intellectualist theories}

There is an anti-intellectualist theory that closely resembles the simple intellectualist theory described above. It holds that knowing what Fs look like is having the ability to know a thing looks W when one knows it is an F. Such a view, in effect, combines the claim that knowing what Fs look like is knowing that Fs look W with an inference-ticket account of knowledge of general facts.

I will not investigate this view further. Any view, such as this one, which identifies knowledge of what Fs look like simply with abilities or dispositions to move from an Fcategorization to an experience/belief/knowledge of the relevant look W cannot satisfy the just- 
see constraint. To satisfy the constraint, the anti-intellectualist needs to appeal instead to abilities or dispositions that take one from the perception of the look $\mathrm{W}$ to the F-categorization. (This claim is slightly qualified below.) The reason for this is that in the target cases the knowledge of what Fs look like has to combine with the perception of the look $\mathrm{W}$ to take one to a knowledgeable F-categorization. An ability that takes F-categorizations as inputs and delivers only an experience, belief, or piece of knowledge of the look $\mathrm{W}$ as outputs will not fit the bill. There is a simple anti-intellectualism that does fit the bill: The simple anti-intellectualist theory: to know what Fs look like is to have the ability to recognize Fs by their characteristic look $\mathrm{W}$; that is, to have the ability to know, upon perceiving an $\mathrm{F}$ as $\mathrm{W}$, that it is an $\mathrm{F}$; in some cases, this ability is not grounded in the possession of factual knowledge.

Here let us allow that it's enough to perceive a thing as W merely to have an experience with the content that the thing is $\mathrm{W}$, that is, an experience as of the thing being $\mathrm{W}$.

This simple theory identifies knowing what Fs look like with an ability that has the inputoutput structure needed to meet the just-see constraint. The ability takes one from the perception of a thing as $\mathrm{W}$ as input to a knowledgeable categorization of the thing as $\mathrm{F}$ as output, rather than vice versa. Take the supermarket case. My ability to know that those are avocados helps position me to know those are avocados insofar as I do perceive them as having this look and by exercising my ability I can come to know that they are avocados. Moreover, if we add that the ability isn't grounded in any knowledge of facts and that in manifesting it I do not draw on any other knowledge of facts, then the epistemizer it makes available to me will be immediate, and the resulting phenomenology will be of "just seeing" the things are avocados. 
The simple anti-intellectualist theory thus meets the just-see constraint and seems to give the liberal dogmatist exactly what is needed to resist the only-because argument. However, it is a false theory. It requires an ability that those who know what Fs look like need not have, as I will now argue. ${ }^{23}$

Suppose, unbeknownst to me, that numerous ringers for human beings - that is, nonhumans that look just like humans -populate my normal environment. (Perhaps I've come to inhabit the world of Invasion of the Body Snatchers.) I'm therefore unreliable when I believe, based on a perception of something that looks like a human, that it is a human being. And so the beliefs I form do not constitute knowledge, even when true. I thus lose the general ability to know human beings by their characteristic looks. ${ }^{24}$ Even still, I don't cease to know what human beings look like. What goes for humans goes for avocados, pumpkins, and pigs. ${ }^{25}$

In response, the anti-intellectualist might substitute dispositions to believe for abilities to know. Even if it's part of my normal environment that there are ringer-humans about, I still have the disposition to believe, when I see a human with the characteristic human-look, to believe it is a human. This disposition would give rise to beliefs that are knowledge in cases in which the environment cooperates.

But what if I know about the presence of ringers throughout my normal environment? Then, over time, I will lose the disposition to believe, of a human I perceive with the humanlook, that it is a human. But I don't lose my knowledge of what humans look like. The trouble is that I know what humans look like while also knowing that the pod-replicas look just like them, and for this reason I lack the disposition to believe a human with the human-look is a human.

The anti-intellectualist may revise her view once again by turning to defeasible dispositions. My knowing what Fs look like requires only being disposed, when I see an F with 
the F-look, to believe it is an F in the absence of evidence that lookalikes abound. So, I retain knowledge of what humans look like even when I come to know that ringer-humans are part of my normal environment. One might invoke the notion of a perceptual seeming to round out such an account: knowing what Fs look like is a disposition, upon perceiving an $\mathrm{F}$ as $\mathrm{W}$, for it to seem to the subject to be an F. In the absence of defeaters, these seemings give rise to beliefs that it is an F.

Yet even this revision isn't enough. Consider: I know what ringers for humans look like. However, I - who do not live in the world of the Invasion of the Body Snatchers - don't have even a defeasible disposition, upon perceiving a ringer for a human with the characteristic look of such ringers - which is also the characteristic look of humans - that it is a ringer for a human. Show me a ringer and I'll be disposed to believe it is a human, not a ringer for a human. So, I know what ringers for humans look like but I lack the corresponding defeasible disposition (as well as all the abilities/dispositions we've previously discussed).

One might reply: knowing what ringers for humans look like is really a different sort of beast; we may give one account of knowing what Fs look like for "well-behaved" categories $F$, like human or avocado and a different sort of account for other "categories" like ringer-for-ahuman or ringer-for-an-avocado.

The problem with this response is that there is a relationship between knowing what Fs look like (for well-behaved F) and knowing what ringer for Fs look like. It is this:

The Ringers Principle: If you understand what ringers are, then you know what Fs look like iff you know what ringers for Fs look like.

The Ringers Principle doesn't say anything about which piece of knowledge is more basic. It merely says that you know one iff you know the other. Do you know what avocados looks like? 
If so, you'll know what ringers for them look like. And vice versa. We should expect a theory of knowing what Fs look like - and of knowing what ringers for Fs look like - to accommodate and explain this principle.

The intellectualist, who accepts our simple intellectualist theory, has no trouble here. The principle is accommodated as follows:

Suppose you understand what ringers are. First, suppose you know what Fs look like. Then you'll know Fs look W. By your understanding of what it is to be a ringer, you know that ringers for Fs look just like Fs. And so you know they too look W. Thus, you'll know what ringers for Fs look like. Next, suppose you know what ringers for Fs look like. Then you'll know that ringers for Fs look W. By your understanding of what it is to be a ringer, you know that ringers for Fs look just like Fs. And so you know Fs, too, look W. Thus, you'll know what Fs look like. Thus, if you understand what ringers are, you'll know what Fs look like iff you know what ringers for Fs look like.

What can the anti-intellectualist do to explain the principle? The anti-intellectualist can't just appeal to the general account of knowing what Fs look like for both Fs and ringers for Fs, of course, for the reasons we've discussed. The question is: what is knowledge of what ringers for Fs look like, so that, if you understand what it is to be a ringer, you know what ringers for Fs look like iff you have the defeasible disposition to believe a thing is an F upon seeing its F-look? The anti-intellectualist can't follow the intellectualist in identifying knowing what ringers for Fs look like with knowing the fact that ringers for Fs look W, where W is the ringer-F look. This wouldn't help explain the Ringer Principle. Why would having the defeasible disposition, upon perceiving an avocado with the look $\mathrm{W}$, to believe it is an avocado, together with understanding what ringers are, guarantee knowledge of the fact that ringers for avocados look W? 
Nor is this the end of trouble. One doesn't strictly need to consider knowing what ringers for Fs look like to see the trouble with the defeasible disposition theory. Consider models of cars that differ only under the hood, hidden from normal viewpoints. Suppose '83 and '84 Toyota Celicas are like this, and suppose I know it. Suppose I own an '83 Celica. I know what '83s Celicas look like and what '84s look like. However, I don't have a defeasible disposition, when I see what is in fact an '84, to believe it is an '84, or even for it to seem to me that it is an '84. Such examples are common ( $\mathrm{CZ}$ and diamonds as well as various illegal substances and legal lookalikes).

One might describe the core problem this way. Knowing what Fs look like doesn't require an ability to go from perceptions of Fs with the look W to categorizations of them as Fs. Yet, in order for the anti-intellectualist to meet the just-see constraint, it appears there is no option but to take knowing what Fs look like to require exactly such an ability. So, the antiintellectualist can't deliver a plausible theory that meets the just-see constraint.

However, the second part of this description is too quick. Yes, to satisfy the just-see constraint, the anti-intellectualist needs to appeal to dispositions taking one from the experiences of Fs with the F-look. And the account needs to explain how we end up with a knowledgeable Fcategorization. But the relevant ability needn't output the F-categorization. It could instead output something closely related: a looks F-categorization. Let's call this the:

Revised anti-intellectualist theory: One knows what Fs look like iff one has the ability to know, upon perceiving an $\mathrm{F}$ with the look $\mathrm{W}$, that it looks like an $\mathrm{F}$, where $\mathrm{W}$ is the look of Fs; and in some cases this ability is not grounded in knowledge of facts. This is still anti-intellectualism, insofar as knowing what Fs look like on this theory in some cases is not grounded in factual knowledge. 
5.1 Why the Revised Anti-Intellectualist Theory Can't Help the Liberal Dogmatist

The revised account avoids all the ringer-related problems considered so far. If there are ringers for humans scattered about my normal environment, I retain my knowledge of what humans look like, because I retain the ability to know upon perceiving a human with the human-look that he or she looks like a human. On this account, moreover, I know what ringers for humans look like, because I have the ability to know upon perceiving a ringer for a human with the ringer-for-ahuman look (the human look), that it looks like a ringer for a human. The Ringers Principle, too, is accommodated. ${ }^{26}$

The revised anti-intellectualist theory is a serious competitor to intellectualism, unlike the simple anti-intellectualist theory and variations on it. For our purposes, though, it doesn't matter whether the revised theory or intellectualism comes out on top. This is because there is a problem with the liberal dogmatist using the revised view to block the last step of the onlybecause argument, a problem that doesn't arise by appealing to the simple view to block that step.

Suppose the revised theory is true. In the supermarket case, how could having the ability to know of some avocados that they look like avocados upon perceiving their looks help position me to know that they are avocados? The ability, together with my experience of the avocados' look, can certainly put me in a position to know that they look like avocados. But how can it help position me to know they are avocados? The only available answer seems to be: it does so by making available an epistemizer that includes my knowledge that those look like avocados. But such an epistemizer includes my knowing a fact and so would be mediate. Thus, the hope of blocking the move from (4) to (5) in the only-because argument vanishes. Recall the step: 
4. Every epistemizer I have for those are avocados includes my knowledge of what avocados look like.

So, 5: My knowledge that those are avocados is not immediate.

The only way 5 could be false if 4 is true (and if, as (1) states, I know those are avocados) is for me to have some epistemizer that includes my knowledge of what avocados look like but doesn't include any factual knowledge. But if the revised theory is to meet the just-see constraint, the epistemizer it makes available for those are avocados includes a piece of factual knowledge, viz. the knowledge that the things look like avocados.

Thus, the liberal dogmatist cannot appeal to the revised theory to block the last step of the only-because argument against liberal dogmatism.

\section{Other objections to the only-because argument}

Up to this point, we have considered only objections appealing to anti-intellectualism (or nonpropositional intellectualism) to block the last step of the only-because argument. One might hope to block the argument at earlier steps. We now turn to those attempts. As we investigate these, we will need to ask, concerning any such attempt, why the only-because argument should fail at a particular step in the target cases but not at the corresponding step in the Scott's Height and Bells cases, which seem to be garden-variety cases of purely mediate knowledge. The liberal dogmatist mustn't throw out the baby with the bath water.

In this section, I suggest we set aside anti-intellectualism. An anti-intellectualist has no reason to challenge any but the last step in the argument, the move from (4) to (5). The same goes for non-propositional intellectualism. Standard intellectualism is thus assumed in what follows. 


\subsection{Against (4): an objection from the child development literature}

One might deny that ordinary perceptual knowledge depends on knowing what things look like, on the grounds that small children have ordinary perceptual knowledge but lack the conceptual resources needed to know what things look like. This objection directly attacks step (4) of the only-because argument. (4) follows from (2) and (3), and so the objector might say that one of these steps must be wrong, even if it isn't clear which. I will examine what seems to me the most promising way to develop this objection.

One might defend the claim that small children lack these conceptual resources by appealing to well-known work by John Flavell and colleagues (1983, 1986a, 1986b, 1992) and by Perner (1991), which purports to show that most children under four years of age cannot grasp the distinction between how a thing looks and what it is, that is, between appearance and reality. Next, one might object to step (4) of the only-because argument as follows. These psychologists' work shows that children lack the appearance-reality distinction. If they lack that distinction, they lack the concept of looks. If they lack the concept of looks, they cannot know what various things look like, because such knowledge requires having the concept of looks. Nevertheless, they do know various things by their looks. They know a bird when they see one, for instance. Or a pumpkin or an avocado.

So far the objection doesn't touch step (4). (4) could be true of normal adults - who are the characters in the target cases - but false of many three-year-olds.

The objector might continue: we adults, when we know a thing is an $\mathrm{F}$ in the target cases, are positioned to know this by the factors that position the three-year-old to know such things, and perhaps other factors as well; since it isn't knowledge of what Fs look like that positions the 
three year-old to know it, there must be some epistemizer not including this knowledge that positions us as well as the three year-old to know the thing is an F. Thus, step (4) is false, even when it is restricted to normal adults.

There are several ways to block this objection. First, it is not clear why we should think that adult knowledge must have an epistemizer in common with the three-year-olds' knowledge. Both must satisfy the conditions for knowledge, of course, but the resulting knowledge could be immediate in one case even if not in the other. ${ }^{27}$ Moreover, if Flavell (1986b, 418-9) is right about very significant changes in the conceptual repertoire of older children, this difference in epistemizers wouldn't be surprising.

Second, on at least one candidate intellectualist account of what it is to know what Fs look like, this knowledge doesn't require having the concept looks. This is option (d), according to which knowing what Fs look like is knowing the fact that Fs are W, where W is the look of Fs. Taking this option seems on the table. ${ }^{28}$

Finally, recent work in psychology calls into question the strong claims about children's failure to understand the appearance/reality distinction. For example, as the psychologists Hansen and Markman (2005) have shown, once experimenters make adjustments to avoid difficulties with the pragmatics of the questions asked in standard Flavell-style appearance/reality tasks, the observed results were markedly different, suggesting a much better grasp of the appearance-reality distinction on the part of three-year-olds. 293031

6.2. Against premise (2): appealing to enabling conditions

Suppose I have an immediate epistemizer, and so one that doesn't include my knowing what avocados look like, which we are assuming is factual knowledge. It would seem that if I 
didn't know what avocados look like, I'd still have this epistemizer and so I'd still be in a position to know those are avocados. That is, it would seem premise (2) ought to be true. But, according to the objection we now consider, this appearance is misleading: although I have an immediate epistemizer, whether I'm positioned to know counterfactually depends on the knowledge about avocados' looks.

The key questions someone making such claims must answer are these: what is the immediate epistemizer, and why would it be that if I lacked the factual knowledge of what avocados look like I wouldn't be positioned to know those are avocados via this same immediate epistemizer? We'll consider the two most promising proposals for the identity of the immediate epistemizer, one appealing to a recognitional ability and the other to an experience with a rich content. Then we'll turn to accounts attempting to explain why, if I have one of these immediate epistemizers, I shouldn't be positioned to know those are avocados if I lacked a seemingly unrelated piece of factual knowledge about looks.

On the ability proposal, the immediate epistemizer includes the possession of a recognitional ability. Let's not worry about the details of which precise ability this is. The idea behind the ability proposal is that the anti-intellectualist is right about the identity of the immediate epistemizer even if wrong to identify having that ability with knowing what avocados look like.

On the rich content proposal, the immediate epistemizer includes my having an experience with a higher-level or rich content, for instance an experience representing the things I see as being avocados. This proposal is attractive. Siegel (2010) makes a strong case that after developing perceptual expertise with things of a certain kind your experience when you see a thing of that kind is phenomenally different from the experiences of those without the expertise, 
and that the best explanation of this difference is a difference in what the experiences represent: experts' experiences represent the tree as a pine tree; non-experts' experiences don't. Rich content, moreover, seems to track who is in a position to enjoy the just-see phenomenology and who isn't. Finally, assuming there is no obstacle to immediate perceptual knowledge in general, it might seem I don't need any special background knowledge to gain knowledge that those are avocados by relying on my experience as of their being avocados. So the epistemizer involving rich content seems to be a good candidate for an immediate epistemizer. ${ }^{32}$

On either of these proposals, why should it be that if I didn't know what avocados look like I wouldn't be in a position to know those are avocados? Why wouldn't I still be positioned to know this thanks to the immediate epistemizer I in fact have?

The most effective general strategy in epistemology for explaining away apparent epistemic mediation is to appeal to enabling conditions. Enabling conditions for an epistemizer are conditions that do not figure in the epistemizer itself, nor in a more fundamental epistemizer by virtue of which the epistemizer positions one to know, but which still help make the epistemizer possible. Below we consider whether knowledge of what avocados look like might be an enabler of the immediate epistemizer. To have a plausible enabling story, more needs to be said about how the enabling works. A satisfactory account should show us that the sort of enabling asserted here is familiar in epistemology, rather than an ad hoc posit.

There are broadly two ways an enabler can enable. One way is by helping to make possible the existence of the factor that is in fact the epistemizer. Call such enablers existence enablers. A familiar example of an existence enabler is the possession of the necessary concepts. I have an epistemizer for my belief that in 2015 Obama is the one of the most powerful political leaders in the world. My epistemizer for this belief includes the factual knowledge that in 2015 
Obama is the US president. To have this epistemizer, I must grasp the concept of a president. Grasping this concept helps make it possible for me to have the epistemizer even though it isn't included in it or in any epistemizer I have for the proposition in question.

A second way an enabler may enable is by helping making it possible for a given factor to qualify as an epistemizer, that is, to put one in a position to know. Call these function enablers. The most familiar function enablers in epistemology concern the lack of defeat. For instance, in the case of testimony, lacking evidence that your interlocutor is insincere is often classified as an enabler of the testifier's testimony justifying you in believing that p. Suppose this lack were absent. Suppose, that is, that I had evidence my interlocutor was insincere. This wouldn't take away the existence of what in fact justifies me in believing that $\mathrm{p}-$ my interlocutor would still have testified and I'd still know it. Moreover, her telling me that $\mathrm{p}$ would still provide prima facie justification. But it would be defeated, and so I wouldn't be (ultima facie) justified. These ideas extend to the case of knowledge, assuming (as I do) that knowledge requires justification. I might be positioned to know that $\mathrm{p}$ by virtue of being reliably and correctly told that $\mathrm{p}$, but this positioning depends on my lacking defeaters. Call my epistemizer E. If I had the defeater, E would have obtained but failed to position me to know that $\mathrm{p}$.

Both sorts of enablers predict the required counterfactual dependence on the enabler. If you lacked an existence enabler, you'd lack the epistemizer that it enables, and so wouldn't be positioned to know by it. If you lacked a function enabler, the factor that in fact is your epistemizer would or might still exist but it wouldn't be an epistemizer and so wouldn't position you to know. We'll consider both categories of enablers, starting with function enablers.

One might think premise (2) of the only-because argument can be shown false by appealing to defeat. The claim would be that if we take away my knowledge of what avocados 
look like, then the factor that in fact provides me prima facie immediate justification would still exist but wouldn't provide me immediate justification - the prima facie justification would be defeated. Assuming justification is required for being positioned to know, I would lack an immediate epistemizer for $\mathrm{p}$, even if the factor that in fact is my immediate epistemizer for $\mathrm{p}$ would still exist.

Suppose for a moment that I'd still have the ability or rich content experience if I were to lack the knowledge of what avocados look like. Why think the ability or experience would provide defeated prima facie justification? What would the defeater be? Using normal forwardtracking counterfactual reasoning, when one asks what would be the case if I didn't know what avocados look like one doesn't conclude that I would have had evidence the lighting was abnormal, that there were many avocado ringers about, etc. ${ }^{33}$

More importantly, though, I wouldn't have had the ability or rich content experience if I lacked the knowledge of what avocados look like. If didn't know what avocados look like, I wouldn't have the ability to know avocados by their looks or whatever other ability/disposition seems a good candidate for inclusion in an immediate epistemizer. Dmitri doesn't. And I wouldn't see these things as avocados. Again, Dmitri doesn't.

If one wants to appeal to enablers to argue that (2) is false, one should appeal to existence enablers rather than function enablers. The question one must then answer is how in the supermarket case my knowledge of what avocados look like helps makes it possible for me to have a rich content experience or to have an ability to know avocados by their looks, and how it does so without helping comprise a more a fundamental epistemizer from which the epistemizer involving the rich content or the ability derives. 
One sort of account is unavailable, viz. the account according to which knowledge of what avocados look like makes available an inferential structure such as (i) - (v), the availability of which grounds the ability to know them by their looks (or the capacity to have experiences as of avocados). On this account, it is hard to see why the epistemizer provided by the ability or the rich content experience wouldn't merely derivatively position me to know that those are avocados, due to my being positioned to know this proposition by an epistemizer including the factual knowledge of what avocados look like, in which case that knowledge isn't serving a merely enabling role.

Our objector needs to explain how the knowledge of what avocados look like is an existence enabler in a way that has nothing to do with this knowledge making available any inferential structure such as (i) - (v). The one clear way to do this is to claim that the knowledge of what avocados look like merely causally sustains the immediate epistemizer. This knowledge must merely causally sustain my possession of the ability or my having the capacity to enjoy the rich content experience.

This causal sustaining account predicts the falsity of premise (2). Counterfactual dependence relations are sensitive to causal relations. So it isn't surprising, assuming that the knowledge of what avocados look like causally sustains the immediate epistemizer, that if you took away that knowledge you'd take away the immediate epistemizer.

One worry about this account is that it doesn't explain an additional fact about the relation between the knowledge of what avocados look like and the epistemic status of the resulting belief that those are avocados. Wiggling the epistemic status of the knowledge of what avocados look like so that it is not knowledge but a true belief lacking even prima facie justification should have no effect on the existence of the immediate epistemizer if the relation 
were purely causal and had nothing to do with inferential structures such as (i) - (v). But it seems to have precisely such an effect. Suppose I didn't know what avocados looked like but had a true unjustified belief that they looked W, where indeed I lacked even prima facie justification for this belief - a mere lucky guess. On the causal sustaining account, merely taking my knowledge and removing its status as prima facie justified shouldn't disturb any currently existing causal sustaining relations, and so should leave in place the immediate epistemizer and so should have no effect on whether the resultant belief that those are avocados is knowledge. And yet it does.

The most troubling aspect of the causal sustaining account, though, is its ad hoc character. Perhaps I need to start out with knowledge about looks in order to develop the relevant ability or to have the capacity to enjoy the relevant rich content, but why couldn't this knowledge drop out later? Why does it need to remain present now to causally sustain these abilities/capacities? The natural answer is that it must remain present in order to ground them through an inferential structure. But if that isn't the answer, it is hard to see what the answer could be.

I have not discussed objections to step (3), which is the claim that 'if I didn't know what avocados looked like, I wouldn't be in a position to know those are avocados." In principle, rejecting (3) is an option. However, would need a good reason, other than the need to save liberal dogmatism, to think (3) is false while the parallel counterfactuals in the Scott's height and Bells cases are true. And we would need an explanation of why the two most plausible candidates for the immediate epistemizer themselves seem to counterfactually depend on my knowledge of what avocados look like. As noted above, it seems that if I didn't know what avocados look like, I wouldn't have the ability to know them by their looks and I wouldn't see them as avocados. In the absence of these explanations, the option of rejecting (3) can be set aside. ${ }^{34}$ 


\section{Whither dogmatism?}

If what I've argued above is correct, liberal dogmatism is false. Our perceptual knowledge in ordinary cases like the supermarket case (you see the avocados and know they're avocados), the office case (you see the pumpkin on the desk and know it's a pumpkin) and Austin's pig case (you see the beast and just know it's a pig) do not amount to immediate knowledge. Could we agree to this but continue to accept some form of dogmatism?

I tentatively suggest that we can. Consider the perceptual belief concerning an object of visual perception this looks $W$. This is a proposition about how things are in the external world, not about my experience. The fact that a thing looks a certain way is not a fact about my having an experience. The thing would look that way even if I weren't looking at it and indeed even if I didn't exist at all. Things' looks are objective in at least that modal sense. So, some non-trivial propositions about the world around us could, for all I have argued, be known immediately.

Might immediate visual knowledge extend beyond the range of propositions about the looks of things, for instance, to perspective-invariant sensible properties such as being red or being round? I leave this open for the purposes of this paper. The key question is whether the same sort of only-because argument I've given about the target cases would be as plausible for knowledge that something is red, or round. Knowing what red looks like, I am in a position to know of a sample in a paint store that it is red. Intervene to take away the knowledge of what red looks like. Would I still be in a position to know the chip was red? For comparison, imagine Frank Jackson's Mary were to join me in the store (immediately upon release from her black and white room). She wouldn't know the paint chip was red. If I didn't know what red looked like, wouldn't I be in her position with respect to whether the chip was red? I will not try to answer 
these questions, but on first blush, it seems that the only-because argument goes through just as well in these cases. The dogmatism we are left with might turn out to be quite restrictive.

Many further projects remain. I have not discussed ways one might come to know what Fs look like. Nor have I discussed in any detail de re knowledge concerning categories, such as what it takes to know of a category that this is an instance of it, or what it takes to know of a category $\mathrm{F}$, that a thing looks like one of those. Much remains to be done to develop a coherent and plausible perceptual epistemology around the ideas of this paper. But I hope to have shown that factual knowledge concerning looks deserves a position of center stage in perceptual epistemology.

\section{Works Cited}

- Alston, William. 1983. "What's Wrong with Immediate Knowledge?" Synthese, 55 (1): $73-$ 95.

- Alston, William. 1993. Perceiving God: The Epistemology of Religious Experience. Ithaca, NY: Cornell University Press.

- Audi, Robert. 2003. Epistemology: A Contemporary Introduction to the Theory of Knowledge. New York: Routledge.

- Austin, J. L. 1962. Sense and Sensibilia, ed. G. J. Warnock. Oxford: Oxford University Press.

- Baddeley, Alan, Michael W. Eysenck, and Michael C. Anderson. 2009. Memory. New York: Psychological Press.

- Bengson, John and Marc A. Moffett. 2007. "Know-How and Concept Possession," Philosophical Studies 136: 31-57. 
- Bengson, John and Marc Moffett. 2011b. "Non-Propositional Intellectualism." In Knowing How: Essays on Knowledge, Mind, and Action, ed. John Bengson and Marc Moffett, 161195. Oxford: Oxford University Press.

- Brewer, William and James Treyens. 1981. "Role of Schemata in Memory for Places," Cognitive Psychology 13: 207-230.

- Briggs, Rachel. 2012. "Interventionist Counterfactuals," Philosophical Studies 160 (1): 139_ 166.

- Brogaard, Berit. 2011. "Knowledge-How: A Unified Account." In Knowing How: Essays on Knowledge, Mind, and Action, ed. John Bengson and Marc Moffett, 136-160. Oxford: Oxford University Press.

- Byrne, Alex. 2014. "McDowell and Wright on Anti-Skepticism etc." In Scepticism and Perceptual Justification, ed. Dylan Dodd and Elia Zardini, 275-297. Oxford: Oxford University Press.

- Cath, Yuri. 2011. 'Knowing How without Knowing That.” In Knowing How: Essays on Knowledge, Mind, and Action, ed. John Bengson and Marc Moffett, 113-135. Oxford: Oxford University Press.

- Chisholm, Roderick. 1957. Perceiving. Ithaca, NY: Cornell University Press.

- Deák, Gedeon O. and Brian Enright. 2006. "Choose and Choose Again: Appearance-Reality Errors, Pragmatics and Logical Ability,” Developmental Science 9 (3): 323-333.

- Dretske, Fred. 1969. Seeing and Knowing. University of Chicago Press: Chicago, IL. - Feldman, Richard. 2003. Epistemology. Prentice Hall: Englewood Cliffs, NJ. 
- Fish, William. 2012. "High-level Properties and Visual Experience," Philosophical studies 162: 1-13.

- Flavell, John, Flavell, Eleanor, and Frances Green. 1983. "Development of the AppearanceReality Distinction," Cognitive Psychology 15: 95-120.

- Flavell, John, Green, Frances, and Eleanor Flavell. 1986a. 'Development of Knowledge about the Appearance-Reality Distinction," Monographs of the Society for Research in Child Development, 51(1, Serial No. 212).

- Flavell, John. 1986b. 'The Development of Children's Knowledge about the AppearanceReality Distinction," American Psychologist, 41: 418-425.

- Flavell, John. 1992. "Perspectives on Perspective-Taking," in Beilin, Harry and Peter Pufall (eds.) Piaget's Theory: Prospects and Possibilities, 107-140. New York: Psychology Press.

- Genone, James. 2014. “Appearance and Illusion,” Mind 123 (490): 339-76.

- Ginet, Carl. 1975. Knowledge, Perception and Memory. Dordrecht: D. Reidel Publishing. - Goldman, Alvin. 2008. "Immediate Justification and Process Reliabilism." In Epistemology: New Essays, ed. Quentin Smith, 63-82. Oxford: Oxford University Press.

- Hansen, Mikkel, \& Ellen Markman. 2005. "Appearance Questions can be Misleading: A Discourse-Based Account of the Appearance-Reality Problem," Cognitive Psychology 50: 233-263.

- Hellie, Benj. 2007. “'There's Something it's like' and the Structure of Consciousness," Philosophical Review 116 (3): 441-463.

- Huemer, Michael. 2001. Skepticism and the Veil of Perception. Littlefield, CO: Rowman and Littlefield. 
- Klein, Peter. 2008. "Useful False Beliefs.” In Epistemology: New Essays, ed. Quentin Smith, 25-62. Oxford: Oxford University Press.

- Kornblith, Hilary. 2002. Knowledge and its Place in Nature. Oxford University Press.

- Lee, Kok Yong. 2015. "Causal Models and the Ambiguity of Counterfactuals." In LORI 2015, ed. W. van der Hoek et al. LNCS 9394: 220-229.

- Leslie, Sarah-Jane. 2012. "Generics." In The Routledge Companion to Philosophy of Language, ed. Gillian Russell and Delia Graff Fara, 355-367. New York: Routledge.

- Lackey, Jennifer. 2005. "Testimony and the Infant/Child Objection," Philosophical Studies 126 (2): $163-190$.

- Markie, Peter. 2006. “Epistemically Appropriate Perceptual Belief.” Nous 40: 118-42.

- Markie, Peter. 2013. "Searching for True Dogmatism." In Seemings and Justification, ed. Christopher Tucker, 248-267. Oxford: Oxford University Press.

- McGrath, Matthew. Forthcoming. "Looks and Perceptual Justification," Philosophy and Phenomenological Research.

- Moll, Henrike and Michael Tomasello. 2011. "Three-Year-Olds Understand Appearance and Reality—Just Not About the Same Object at the Same Time.” Developmental Psychology 48 (4): 1124-1132.

- Nida-Rümelin, Martine. 1996. “What Mary Couldn’t Know.” In Conscious Experience, ed. Thomas Metzinger, 219-241. Exeter: Imprint Academic.

- Nudds, Matthew. 2011. “Children's Understanding of Perceptual Appearances.” In Perception, Causation and Objectivity, ed. Johannes Roessler, Hemdat Lerman and Naomi Eilan, 264-285. Oxford: Oxford University Press. 
- Oliva, Aude and Antonio Torralba. 2006. "The Role of Context in Object Recognition," Trends in Cognitive Sciences 11: 521-527.

- Palmer, Stephen. 1975. "The Effects of Contextual Scenes on the Identification of Objects," Memory and Cognition 3: 519-526.

- Peacocke, Christopher. 1986. Thoughts: An Essay on Content. Oxford: Basil Blackwell.

- Peacocke, Christopher. 1993. A Study of Concepts. Cambridge, MA: MIT Press.

- Pearl, Judea. 2009. Causality: Models, Reasoning, and Inference, second edition. Cambridge, Cambridge University Press.

- Pryor, James. 2000. "The Skeptic and the Dogmatist," Nous 34: 517-549.

- Recanati, François. 2013. "Perceptual Concepts: in Defence of the Indexical Model," Synthese 190 (10): 1841-1855.

- Sainsbury, R. Mark and Michael Tye. 2012. Seven Puzzles of Thought. Oxford: Oxford University Press.

- Schaffer, Jonathan. 2016. "Grounding in the Image of Causation," Philosophical Studies 173 (1): 49-100.

- Schechter, Joshua. 2013. "Rational Self-Doubt and the Failure of Closure," Philosophical Studies 163(2): 428-452

- Senor, Thomas. 2014. "Epistemological Problems of Memory", The Stanford Encyclopedia of Philosophy, Edward N. Zalta (ed.), URL = $<$ http//plato.stanford.edu/archives/fall2014/entries/memory-episprob/>.

- Siegel, Susanna. 2010. The Contents of Visual Experience. Oxford: Oxford University Press. 
- Silins, Nicholas. 2013. "The Significance of High-Level Content," Philosophical Studies

162: $13-33$.

- Stanley, Jason and Timothy Williamson. 2001. "Knowing How," The Journal of Philosophy 98: 411-444.

- Stanley, Jason. 2011. Knowing How. Oxford: Oxford University Press.

- Tye, Michael. 2009. Consciousness Revisited. Cambridge: MIT.

- Zardini, Elia. 2013. "Knowledge-How, True Indexical Belief, and Action,” Philosophical Studies 164(2): 341-355.

\section{Longer Note}

Must W be Fs' most determinate look property possessed by Fs? I know what zebras look like but do I know a proposition zebras look $W$ where $\mathrm{W}$ is their most determinate look, a look, say that even cleverly disguised mules lack? This seems to ask too much. The intellectualist (and anti-intellectualist, too) plausibly ought to conclude that the determinacy of a look $\mathrm{W}$ in an attribution "S knows what oboes look like" varies with context.

Another issue is whether knowing what Fs look like requires knowing what Fs do not look like. If you know what oboes look like, you'll surely know that oboes don't look W', where W' is a car-ish look, that they don't look W', where this is a book-look, etc. We might therefore want to think about building into our formulations of the truths known clauses such as “... and Fs don't look W1, W2, .., or Wn." One might wonder whether closure principles on knowledge make such clauses unnecessary. ${ }^{35}$

A further complication is that things can have different looks in different situations each of which is a good one for taking in the things' looks. Water looks a certain way in a glass on a 
table, another way in a lake on a sunny day. We might therefore want to expand the simple intellectualist proposal that knowing what Fs look like is knowing that Fs look W to something like:

Fs look W in situation S1 and Fs look W2 in situation S2 and... where the $\mathrm{S}_{\mathrm{i}}$ 's comprise the good viewing situations for Fs. Again, what count as good viewing situations might vary with the context. What goes for viewing situations goes for seasons, times of day, insides of a thing vs. outsides, etc. Think of maple trees in fall vs. spring, loons in winter vs. summer, avocados when cut open vs. in the shell, etc. It also goes for different configurations of parts, a cat curled up on a rug vs. standing upright.

Even more complications: different subcategories of an object category F often have different but related looks. Do you have to know what every subcategory of F looks like to know what Fs look like? That's too strong. You can know what oak leaves look like without knowing what shingle oak leaves look like. But in some cases you might need to know what several subcategories of Fs look like to count as knowing what Fs look like. Do you know what a piano looks like if you don't know what uprights look like but do know what grand pianos look like? Again, context-sensitivity presumably plays an important role.

Because of the context-sensitivity of attributions of knowing what Fs look like, the main arguments of this paper are perhaps better stated in the formal rather than the material mode. ${ }^{36} \mathrm{I}$ will not carry out a complete reformulation here, but I will give the flavor of some of the more important changes. Concerning the only-because argument, one may say that it is valid and that its premises are true in certain contexts, for instance the context of the supermarket or of our thinking about the supermarket case with the sorts of interests we typically have. Similarly, one 
might restate the just-see constraint as a claim to the effect that in those same contexts (ones in which premises of the only-because argument are true) if the attribution of knowing what Fs look like is true then the epistemic property expressed helps position the subject to know the thing is an $\mathrm{F}$ with the required phenomenology. The argument against simple anti-intellectualism, too, could be recast in the formal mode, the guiding idea being that context supplies us a certain look (or set of looks) W to which the subject must bear the proper relations for the attribution of knowing what Fs look like to be true of her, but that once this $\mathrm{W}$ is fixed, it is not necessary for the truth of the proposition expressed that the subject have the ability to recognize Fs by $\mathrm{W}-\mathrm{a}$ conclusion supported by noting that this proposition is true in counterfactual situations in which it is part of the subject's normal environment that there are many F-ringers scattered amongst Fs.

\footnotetext{
* I am grateful to audiences at the University of Massachusetts, Washington University in St. Louis, the University of Arkansas, the University of Glasgow, St. Andrews University, MIT, the University of Arizona and the University of Edinburgh, and to members of the faculty writing group at the University of Missouri for many valuable comments. Special thanks go to Jessica Brown, Herman Cappelen, Robert Cowan, Hilary Kornblith, Kok Yong Lee, Jack Lyons, Mohan Matthen, Susanna Siegel, Nico Silins, Ernest Sosa, and several anonymous readers for this journal.

${ }^{1}$ Examples include Alston (1993), Goldman (2008), Huemer (2001), Kornblith (2002), and Markie (2006). Richard Feldman $(2003,71)$ seems to embrace immediate knowledge in cases very much like our target cases. The rough gloss on immediate knowledge comes from Alston (1985, 73).
} 
${ }^{2}$ Arguably, one's visual experience itself in many cases depends on what the visual system ‘knows.” This doesn't spoil immediacy, though. Immediate knowledge is knowledge a person has which doesn't depend for its status as knowledge on the person's knowledge of other propositions/facts (I do not distinguish true propositions and facts).

${ }^{3}$ There are important exceptions. See Dretske $(1969,82)$, Ginet $(1975$, ch. 6), Lowe $(2000,136)$ and more recently Markie (2013,262-7) and Genone (2014).

${ }^{4}$ A factor E may position one to know that $p$ even if E's obtaining fails to entail that one is in a position to know that $\mathrm{p}$. This happens in ordinary cases of non-deductive knowledge. I know my colleague's office door is open and I know that it would be very unusual if it was open but she was not on campus. My having these pieces of knowledge may well position me to know she is on campus. Suppose they do. Then they comprise an epistemizer I have for the proposition that my colleague is on campus. Still, my having the knowledge that makes up the epistemizer does not entail that I am in a position to know she is on campus. For one thing, my having that knowledge doesn't entail that my colleague is on campus. But even if we include her being on campus as an additional conjunct in the epistemizer, still there is no entailment. What if the janitor, in an unusual turn of events, has been cleaning offices during the daytime hours, or what if I have misleading evidence this is so? Then arguably I wouldn't be position to know she is on campus despite having the two pieces of knowledge. In many cases like this, whether a factor is an epistemizer - whether it positions one to know - depends on whether certain enabling conditions are satisfied. I discuss enabling conditions in detail in section 6.2.

${ }^{5}$ Here I set aside worries about whether a purely psychological basing relation would be sufficient to gain knowledge from factors that position one to know. If further normative conditions are required, they could be added as well. 
${ }^{6}$ For instance, if it is possible, as Klein (2008) argues, to have knowledge based on justified but false grounds, then we would need to revise conditions (i) and (ii) to make sure that an epistemizer including a false justified belief would count as mediate.

${ }^{7}$ Given these definitions, past states of factual knowledge can figure in immediate epistemizers. One could, however, distinguish two notions of an immediate epistemizer, the one I have defined as well as a more demanding one requiring that the epistemizer include no factual knowledge, past or present. If the main argument of this paper succeeds, it shows that in the target cases the subject lacks immediate epistemizers in the weaker sense and so a fortiori in the stronger sense. ${ }^{8}$ Our judgments come comparably fast, whether about "low-level" properties or object kinds. See Fish $(2012,50-2)$ for a summary of results of reaction time studies as well as presentational time studies.

${ }^{9}$ For a clear explanation of an interventionist approach to the logic and semantics of counterfactuals, see Briggs (2012). See also Lee (forthcoming) for an argument that counterfactuals are generally ambiguous between an interventionist reading and what he calls an extrapolation reading. Lee explains these within the causal modeling framework in terms of whether the relevant submodel used to evaluate the counterfactual contains the same structural equations or not. Using the same structural equations allows values of parent variables as well as descendent variables to be affected.

${ }^{10}$ For the moment, I set aside complications stemming from the fact that some factors might position one to know only because other factors do so. I consider these matters in section 4.1. ${ }^{11}$ In effect, one uses the counterfactual to test a proposed epistemic model, just as one might use a counterfactual to test a proposed causal model. For an account of how to apply ideas from causal modeling more broadly in philosophy, see Schaffer (2016). 
${ }^{12}$ See Stanley (2011) and Brogaard (2011) for discussion.

${ }^{13}$ Thanks to Alex Byrne for this proposal.

${ }^{14}$ For noncomparative vs. comparative statements about looks, see the classic discussion by Chisholm (1957, 43-53).

${ }^{15}$ Working from a proposal of Hellie's $(2007,445-8)$, one might identify knowing what Fs look like with knowing that Fs look like that, where 'like that' expresses the way W that Fs look rather than similarity to an object demonstrated. This proposal is subsumed under (a). ${ }^{16}$ For convenience, I'll sometimes use ' $\mathrm{W}$ ' as a noun referring to Fs' look, even though ' $\mathrm{W}$ ' in 'Fs look W' occupies an adjectival position. Throughout, I set aside questions about how to understand looks and ways of looking. However, I do make one metaphysical point about looks (see section 7): looks are properties objects have and which they would have regardless of whether the objects are being seen. For more on the metaphysics of looks, see McGrath (forthcoming).

${ }^{17}$ The idea that a subject's background knowledge can play a role despite the absence of the phenomenology of reasoning is widespread in psychology. For work on the role of background knowledge in object recognition, see for example Palmer 1975 and Oliva and Torralba 2006). In the case of memory, psychologists appeal to memory schemas to explain our beliefs about an object, place, or event. These schemas are often referred to as our "stored knowledge" of categories of information. See Brewer and Treyens (1981) for a classic study, and for general overview see Baddeley et. al. (2009), ch. 6 .

${ }^{18}$ See also Papineau's discussion of perceptually derived concepts, concepts derived from a perceptual concept but including a non-perceptual file in which information about the referent(s) is housed. 
${ }^{19}$ For more on acquaintance, especially as the key to a physicalist-friendly solution to Jackson's knowledge argument, see the earlier proposal by Conee (1994). Tye's intellectualist account gives a nice resolution to variants of the Mary puzzle, including one due to Nida-Rümelin (1996) in which Mary is shown something red but has no way to know whether it is red. According to Sainsbury and Tye $(2012,167)$, although Mary learns something (she gains acquaintance with the phenomenal property, and based on this, learns what it is like to experience that color), she doesn't learn what it is like to experience red. Something similar can be said for the looks of avocados. One might gain acquaintance with the look and come to know that these sorts of things look so, without coming to know what avocados look like. The position of ' $\mathrm{X}$ ', whether singular or plural, in 'S knows what $\mathrm{X}$ look(s) like' is non-extensional, as Sainsbury and Tye (2012, 167) observe.

${ }^{20}$ Having a recognitional concept of a look $\mathrm{W}$, which is in fact the look of Fs, does not entail having the ability to recognize things as Fs by perceiving W. Dmitri from northerly climes might well have seen avocados in supermarkets regularly since moving down south and so he might now have a recognitional concept of this look $\mathrm{W}$. However, consistent with this, he might still lack any ability to recognize them as avocados from their having look $\mathrm{W}$.

${ }^{21}$ Thanks to an anonymous referee for raising this question.

${ }^{22}$ However, see note 6.

${ }^{23}$ The difficulties arising here for the simple anti-intellectualist theory arise for any theory of knowing what Fs look like that takes it to require the ability to recognize Fs by their looks. Thus, they arise for anti-intellectualist theories that identify knowing what Fs look like with objectual knowledge of the way Fs look and take this objectual knowledge to be grounded in the 
possession of the ability to recognize Fs by their looks. Such a view is an analogue of what Bengson and Moffett call non-dispositionalist anti-intellectualism about knowhow (2011b, 166). ${ }^{24}$ The ability to know and the ability to have true beliefs come apart here. In the example, I have the ability to have a true belief, when I see the look W in a human being, that it is a human being. But because my method - to go by this look $\mathrm{W}$ in visually judging a thing human - is unreliable, the resulting beliefs do not qualify as knowledge. I lack the ability to know, when I see look W in what is in fact a human being, that it is a human being.

${ }^{25}$ It does no good for the anti-intellectualist to revise her view by adding further abilities or additional "tracks" to the disposition. The problem is not that knowing what Fs look like requires more than the mere ability to know Fs by their looks. The problem is that it does not require this ability.

${ }^{26}$ The revised view has further advantages over the simple view. Suppose you're visiting Madame Tussauds' wax museum. You know what Barack Obama looks like. That is why you're able to tell that a certain wax statue looks like Obama. On the simple theory, it appears that the only way the fact that you know what Barack Obama looks like could explain your being in a position to know that a certain statue looks like Obama is courtesy of an epistemizer including your knowledge of the fact this is Obama. (You know it looks like Obama only because you know it's Obama, and of course you know that Obama looks like Obama.) But this explanation doesn't work: you don't know it is Obama, since it isn't Obama. Nor are you justified in believing it is Obama. On the revised anti-intellectualist theory, these problems do not arise. 27 The basic point here is not original with me. As Schechter (2012) has argued, the greater cognitive capacities of adults might increase the demands on them in order to be justified or know. He calls this the Spiderman Principle: with greater cognitive power comes greater 
epistemic responsibility. Similarly, Lackey (2005) argues, using the example of testimony, that objections to epistemological views based on the limitations of children create problems even for views positing immediate justification, particularly concerning the non-vacuous satisfaction of no-defeaters conditions.

${ }^{28}$ There is at least one difficulty with it, however. We would lose the simple explanation of the Ringers Principle. However, consider the following explanation. Suppose I understand what ringers are. Suppose next that I know that avocados are W. How can I know that ringer-avocados are W? Perhaps merely adding the knowledge that $\mathrm{W}$ is a look will do it. For then I know that avocados have the look $\mathrm{W}$, and so can conclude that ringer-avocados do, too, and so can conclude that they, too, are W. And the converse may hold as well for analogous reasons. ${ }^{29}$ In the standard Flavell paradigm, the experimenter's appearance question is neutral on what the object is. A child is shown an eraser that looks like a chocolate bar and asked, "What does this look like?" Hansen and Markman $(2005,245)$ found that when the identity of the object is presupposed in the question, correct answers to appearance questions soars. For the standard appearance question, $47 \%$ of answers were correct; for the revised appearance questions, $91 \%$ were correct. In another task $(2005,252)$, experimenters asked children to explain to a doll, "what this and what it looks like," and again the children performed very well. $81 \%$ of the children explained this correctly as compared with only $38 \%$ of children who answered both the appearance and reality questions correctly in a standard Flavell task. For a discussion of further pragmatic problems with Flavell's experiments, see Deàk and Enright (2006). See also Nudds (2011).

${ }^{30}$ Controversy remains over the richness of three-year-olds' understanding of the distinction. For instance, Moll and Tomasello (2011) claim that while three year-olds have the appearance/reality 
distinction, they lack the ability to "confront" the appearance perspective with the reality perspective. The children have the distinction but haven't yet mastered it.

${ }^{31}$ A more general worry one might raise at this point is whether the intellectualist picture is consistent with leading theories of object recognition and identification in cognitive psychology. I cannot address this question in the detail it deserves here. Briefly, though: it is commonplace within cognitive psychology to think of object recognition as involving four stages (Palmer 1999, 413): object representations ("the to-be-categorized object must be perceived and represented within the visual system"); category representations (possible categories must be "represented in memory in a way that is accessible to the visual system"); a comparison process (the object representation is "matched or compared against possible category representations"); and a decision process (based on the comparison process, a decision must be made as to an object's category). As Byrne (2014) remarks, there seems to be little place in such theories for beliefs about experiences. This may be correct. Although experiences themselves may enter into the object representation stage, representations about experiences don't obviously enter in. However, the intellectualist appeals rather to representations associating categories with looks, sounds, etc., These might be thought to enter at the category representation stage and presumably at others as well.

${ }^{32}$ For a discussion of the relevance of issues of high-level content to epistemology, see Silins (2013).

${ }^{33}$ Nor do we conclude that various external conditions obtain that might spoil a factor's positioning one to know. We don't conclude, for instance, there would have been many ringeravocados nearby. 
${ }^{34}$ In an interesting recent paper, Markie (2013) argues that in cases like the target cases one's justified belief that a thing seen is an $\mathrm{F}$ is justified in virtue of being an exercise of a recognitional ability, one which is "determined" by the possession of background information (in the form of justified beliefs and experiences) that give one prima facie justification for the information that "what looks a certain way is [an F]." Markie denies that the background information causes the ability, claiming that it "informs" it, accounting for why one is disposed to have this particular reaction to that particular look. He claims that his proposal allows the resulting belief to be immediately justified, insofar as the belief isn't based on other justified beliefs.

However, to save liberal dogmatism (even of a qualified form that handles apparent counterexamples to dogmatism from cases of cognitive penetration, which is Markie's focus in the article), Markie must deny some step of the only-because argument for the supermarket case. Though he seeks an important role for information about looks, he must deny that factual knowledge concerning looks enters into every epistemizer for the belief that those are avocados. It is difficult for me to see how he can do this, while giving such information an essential role, unless he appeals to enabling conditions.

Markie's proposal is similar to mine in giving a central role to information about looks in explaining perceptual justification. There are noteworthy differences, though, in addition to our difference over whether the information about looks compromises epistemic immediacy. Markie does not appeal to knowledge of what Fs look like. He appeals, as we've seen, instead to having the information that what looks a certain way is an F, or in other words that what looks W is an F. (This is not a good candidate for knowing what Fs look like: one can know what humans look like without knowing that what has the look $\mathrm{W}$ are humans, as the Invasion of the Body 
Snatchers cases show. Markie doesn't claim otherwise.) Assuming standard intellectualism, I would agree with Markie that the information what looks $W$ is an $F$ plays an important role (I would claim a mediating epistemic role) in supporting the knowledge that the thing is an F. However, in the target cases, and in the cases Markie discusses, I claim the information what looks $W$ is an $F$ is epistemically downstream from the information that Fs look $W$. This knowledge comes from knowledge of what Fs look like together with the knowledge that Fs have a distinctive look.

35 The logic of generics, and of the various kinds of generics, will matter here. To use an example from Sarah-Jane Leslie (2012), one can know that ducks lay eggs and know that egglaying implies being female but not know that ducks are female. This is not a counterexample to the closure of knowledge under known implication. Rather, it is a counterexample to the claim that all inferences from $F$ s are $G$ and being a $G$ entails being an $H$ to $F$ s are $H s$ are valid. It might be possible to reinstate some such inferences for certain sorts of generics (not including "striking generics"), in which case closure could be applied.

36 Thanks to Herman Cappelen for helpful discussion of the issues discussed here. 